\title{
Bio-characterization of Some Free Living Amoebae in the Surface Water of the City of Yaounde: Relationship to Physico-chemical Parameters of the Medium
}

\author{
Kapso Tchouankep Mireille \\ Laboratory of Hydrobiology and Environment, University of Yaounde 1, Cameroon \\ E-mail: mirellekapso@yahoo.fr Tel: 0027696711733/672779664 \\ Ajeagah Gideon Aghaindum (Corresponding author) \\ Laboratory of Hydrobiology and Environment, University of Yaounde 1, Cameroon \\ E-mail: ajeagahg@yahoo.com Tel: 00237675916857
}

Nkeng George Elambo

Ecole Nationale Supérieure des Travaux publics. E-mail: gnkeng@yahoo.com

Ngassam Pierre

Laboratory of Hydrobiology and Environment, University of Yaounde 1, Cameroon

E-mail: mbeungassam@yahoo.fr Tel: 002377679237093

Received: July 26, 2017 Accepted: February 1, 2018 Published: February 5, 2018

Doi: 10.5296/jab.v6i1.12605 URL: http://doi.org/10.5296/jab.v6i1.12605

\begin{abstract}
A study was carried in Yaounde to evaluate the level of organic pollution in the surface water and to determine the distribution of pathogenic free living amoeba in the aquatic ecosystem. Six points were selected on the Olezoa and the Abiergue streams of Yaounde for our study. Physico-chemical pollution was carried out by standard methods of assessment. The parameters measured were suspended solids, electric conductivity, pH, TDS, Oxydability,
\end{abstract}


BOD5, COD, humidity, Dissolved Oxygen. The free living amoeba were identified by direct observation on microscope and observation after culture on Non Nutritive Agar (NNA)and Page's Agar Saline Solution (PAS) which are all enriched with Escherichia coli. The data obtained reveal a high pollution of these urban streams of the Mfoundii River system and presents a high densities of telluric amoebae such as Acanthamoeba (21 Cell./L), Balamuthia (11 Cell./L), Naegleria (6 Cell./L), Vanella (17 Cell./L) and Vermamoeba (5 Cell./L). The sizes vary between 12 to $94 \mu \mathrm{m}$ for the different forms isolated and identified in our study. The presence of amoeba are significantly correlated with hydrometry, temperature, nitrates suspended solids, COD and $\mathrm{BOD}_{5}(\mathrm{p}<0.001)$. These organisms in water show contamination of the groundwater by wastewater during the study period.

Keyswords: Contamination, Surface water, Free living pathogenic amoebae

\section{Introduction}

Pollution and water scarcity are major factors in most countries in the African continent. The aspects and scope are different according to the levels of development of the different nations. In Cameroon, in particular, populations are faced with problems of access to drinking water and wastewater management (Braun et al., 2005). Due to the absence of wastewater collection, treatment and disposal networks, much of the untreated sewage (hospital, domestic and industrial waste) is discharged directly into the environment. This waste has an adverse effect on the environment and on the health status of the population because it conveys diseases such as amibiases to brain meningitis (known as primary amoebic meningoencephalitis (PAM), including amoebic keratitis and other low water quality related diseases. For example Naegleria fowleri can cause lethal infection of the brain Blair et al., 2008).

Amoebae are found in all natural environments (soils, rivers) and artificial (dwellings, water systems). These protozoa are capable of harbouring, protecting and dissemination of known or emerging pathogenic micro-organisms such as virus, bacteria and fungi (Thomas, 2012; Moreno-Mesonero et al., 2015). Moreever, some of these amoebae in the cystic form are very resistant to disinfection or decontamination treatments (Moreno-Mesonero et al., 2015). Thus, a good follow-up of the quality of water passes by a good knowledge of its microbiological quality. The aim of this study is to isolate and identify free living pathogenic amoebae in the surface water of Yaounde and to determine the role of physico-chemical variables in their distribution.

\section{Materials and Methods}

\subsection{Geographical Location of Sampling Stations}

Yaoundé is the political capital of Cameroon which is situated in the centre Region. It is located in the forest region of the southern plateau between latitudes $3^{\circ} 30^{\prime}$ ' and $3^{\circ} 58^{\prime}$ North and longitudes $11^{\circ} 20^{\prime}$ and $11^{\circ} 40^{\prime}$ East with an altitude of about $750 \mathrm{~m}$. The relief of this town is undulating with an alternation of hills and valleys which are gorged with water (Wethé, 2003). The town is characterised by an abundant precipitations of about $1576 \mathrm{~mm} / \mathrm{year}$ which may vary over the year. The climate is the equatorial type known as Yaoundeen that is, hot and humid, which varies slightly over time. The meteorology of this town shows the following characteristics: a long dry season (LDS) which begins from mid-November to mid-march, a short rainy season (SRS) which starts from mid-march to ending June, a short 
dry season (SDS) which starts from July to the end of August and a long rainy season (LRS) which begins from September to mid-November. These climatic variations are unstable with an average annual temperature of $24.55 \pm 2.6^{\circ} \mathrm{C}$ (Suchel, 1987). The hydrographical network is dense, constituted of many streams and their tributaries which empty themselves in the Mfoundi River. The soil is azonal and composed mainly of ferro-laterites (Wéthé et al., 2003).

\subsection{Presentation of the Study Site}

This research work was conducted over a period of 13 months beginning from the month of March 2015 to March 2016.It all started with the prospection that enabled the selection of the Olezoa and Abiergue streams and the different sampling points based on a number of factors such as: pollution source, use of water, population density, lack of adequate sanitation and precarious hygiene and its accessibility among others. The Olezoa stream takes its source from the north-east region under a rock behind the Amphitheatre 700 of the University of Yaounde I, its source is of the rheocrene type with the velocity and flow rate being relatively slow. It flows from the slope of the Ngoa-Ekelle hill, passing through many quarters and neighbourhoods with a considerable speed. Flowing into lake Obili which is an artificial eutrophic lake use for pisciculture, it continues its flow through the Bonanossadi, Cradat and the Olezoa neighbourhoods, from where it continues its flow through the marshy areas and farms below the military football field, the French avenue, to finally empty itself in the River Mfoundi (INC, 2008). A total of three points were chosen along the stream denoted as upstream $\left(\mathrm{O}_{1}\right)$, lake $\left(\mathrm{O}_{2}\right)$ and downstream $\left(\mathrm{O}_{3}\right)$ Figure 1 and $2 . \mathrm{O}_{1}$ is located in Latitude $3^{\circ} 51.555^{\circ} \mathrm{N}$, longitude $11^{\circ} 30.145^{\circ}$ Eat an altitude of $747 \mathrm{~m}, \mathrm{O}_{2}$ is located in Latitude $03^{\circ} 51.388^{\circ} \mathrm{N}$, longitude $11^{\circ} 29.718^{\circ} \mathrm{E}$ at an altitude of $731 \mathrm{~m}, \mathrm{O}_{3}$ is located in Latitude $03^{\circ} 51.092^{\circ} \mathrm{N}$, longitude $11^{\circ} 29.746^{\circ} \mathrm{E}$ at an altitude of $725 \mathrm{~m} . \mathrm{O}_{1}$ is situated about $500 \mathrm{~m}$ after the source precisely below the school of engineering. The station is characterized by the presence of farmlands and homes. Water crosses latrines, poultry farms, piggery and garbage. Accessibility is achieved by a foot path created by the inhabitants to facilitate movements to their farms. $\mathrm{O}_{2}$ is situated some $1 \mathrm{~km}$ from the source. This lake measures about $60 \mathrm{~m}$ large, $100 \mathrm{~m}$ long and about $1.5 \mathrm{~m}$ deep, it is use for fish culture such as, Oreochromis, Hemichromis, Heterotis and Clarias. Around the lake is a huge garbage pit, farmlands, homes and a pisciculture practising centre. This lake suffers a great deal of eutrophication due to the accumulation of nitrates and orthophosphates in the effluent. The station $\mathrm{O}_{3}$ is situated about some $500 \mathrm{~m}$ from $\mathrm{O}_{2}$ below the lake ecosystem (Figure 1). The presence of suck-away pipes from latrines that empty themselves directly into the stream. The sources of contamination are agricultural wastes, pisciculture, and domestic and hospital wastewater. Some inhabitants around this area use water from this station for laundry, car and motor bike wash and for agriculture. The choice of this site was due to its high degree of pollution coming from household wastes and effluents deposited inside the stream by the inhabitants living nearby or closer to this stream. 


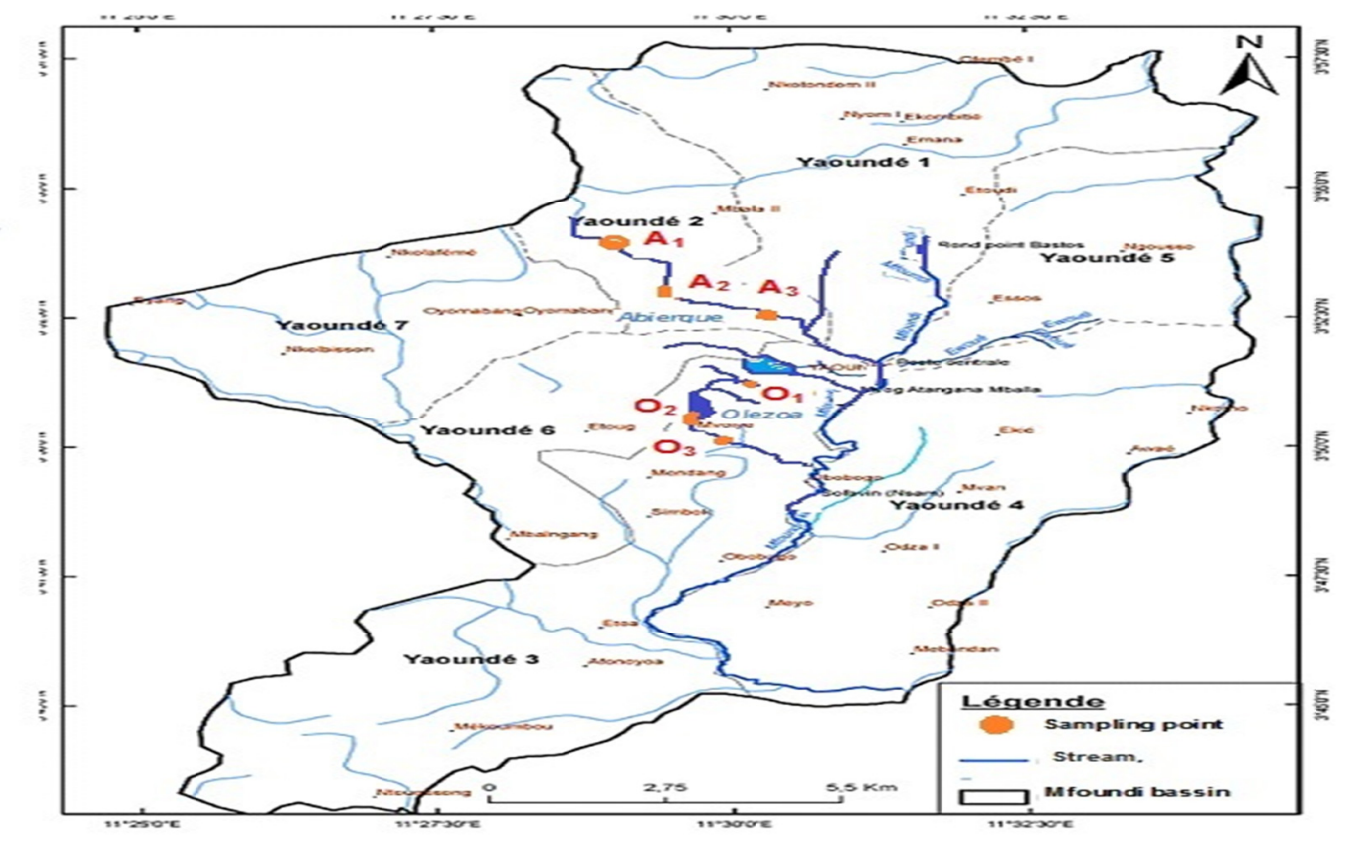

Figure 1. Map of Yaounde showing the different sampling points on Olezoa and Abiergue (source INC, 2008 modifié)

The Abiergue stream is oriented West-North-West, East South-East and about $5.2 \mathrm{~km}$ long. It originates at an altitude of $775 \mathrm{~m}$ in the Olinga district. In the Nkonkana district, it crosses the Nkonkana market and a site of artisanal slaughter of animals. The stream flows through the neighbourhoods of Ntougou II, Mokolo and Briqueterie. Three sampling stations enable us to biologically and physico-chemically characterize this watercourse at the stations $A_{1}, A_{2}$ and $\mathrm{A}_{3}$ as presented in figures 1 above.

A1 is located in Latitude $03^{\circ} 53.152^{\circ}{ }^{\circ} \mathrm{N}$, longitude $11^{\circ} 29.476^{\circ} \mathrm{E}$ at an altitude of $746 \mathrm{~m}, \mathrm{~A} 2$ is located in Latitude $03^{\circ} 52.448^{\circ} \mathrm{N}$, longitude $11^{\circ} 29.581^{\circ}{ }^{\circ} \mathrm{E}$ at an altitude of $723 \mathrm{~m}$, A3 is located in Latitude $03^{\circ} 52.448^{\circ} \mathrm{N}$, longitude $11^{\circ} 29.581^{\circ}{ }^{\circ} \mathrm{E}$ at an altitude of $710 \mathrm{~m}$, The $\mathrm{A}_{1}$ station is about $100 \mathrm{~m}$ from the road crossing the Nkonkana market. Upstream of this point is the slaughterhouse of small livestock, whose discharges of water and waste directly flows into the stream. The $\mathrm{A}_{2}$ station is located in the Mokolo district of the municipality of Yaounde. On its right bank there is a garbage dump, a bleach toilet and craft pot factories. The $A_{3}$ station is located in the lower course a few meters from the bridge behind the sports palace, about 200 meters upstream from the confluence with the Ekozoa stream. The sources of contamination are a market, slaughter house, artisanal fabrication, urban agriculture A Garmin MAP 76 Gep-positioning system (GPS) receiver was used to determine the geographical coordinates (Longitude, Latitude and Elevation) of the sampling points.

\subsection{Physicochemical Parameters}

The physicochemical analyses proceeded at the same time on the ground and at the laboratory following the Some physicochemical parameters where measured on the field directly and others in the laboratory following the recommendations of Rodier et al., (2009). In the laboratory, suspended solids, turbidity and the color, the nitrates, nitrites, orthophosphates 
and COD were measured by colorimetry with spectrophotometer DR/3900HACH (manufacturer?). Dissolved $\mathrm{CO}_{2}$, alkalinity and oxydability were measured by volumetry after the application of the appropriate reagents. BOD5 by respirometry with a BOD incubator of mark LIEBHERR.

\subsubsection{Temperature and Humidity}

Temperature was measured using an alcohol thermometer graduated in $1 / 10^{\circ} \mathrm{C}$. The thermometer was submerged into the stream for about 3 minutes and the temperature values read and recorded. The relative humidity (in percentage) was measured using a CANDY electronic moisture meter.

\subsubsection{Suspended Solids and Turbidity}

Suspended solids and turbidity were measured in the laboratory by colorimetric analysis using a spectrophotometer of mark HACH DR/3900 at a wavelength of $810 \mathrm{~nm}$, and $450 \mathrm{~nm}$ respectively. Their values were expressed in $\mathrm{mg} / \mathrm{L}$ for suspended solids and Formazine Turbidity Unit (FTU) for turbidity.

\subsubsection{Colourand Total Dissolved Solids (TDS)}

Colour was measured in the laboratory using a spectrophotometer of mark HACH DR/3900, over a wavelength of $455 \mathrm{~nm}$ and the results expressed in units of Platinum Cobalt (Pt.Co). TDS was measured in the laboratory using a TDS/Conductimeter of mark HANNA. The electrode of the instrument was dipped into the water sample for about 2 to 3 minutes. The results read were expressed in $\mathrm{mg} / \mathrm{L}$.

\subsubsection{Hydrogen Potential $(\mathrm{pH})$ and Electric Conductivity}

Electric conductivity andpH were measured using a checker portable of mark HANNA model HI 9829 with a resolution value of 0.01 . 2/3 of the electrode was dipped into the water sample for about 2 minutes and the values were read on the screen. The $\mathrm{pH}$ value was evaluated in conventional unit and electric conductivity results obtailned or read were expressed in micro-siemens per centimetre $(\mu \mathrm{S} / \mathrm{cm})$

\subsubsection{Dissolved Carbon dioxide $\left(\mathrm{CO}_{2}\right)$}

Its measurement involved two steps, insitu and in the laboratory. Insitu, $20 \mathrm{~mL}$ of $\mathrm{NaOH}$ $\mathrm{N} / 20$ was measured using a measuring cylinder and poured into a $200 \mathrm{~mL}$ volumetric flask to which 2 to 3 drops of phenolphthalein indicator were added, producing a characteristic pink colour, the flask was completed with water sample to the $200^{\text {th }}$ mark of the flask. The mixture was then transferred into a $250 \mathrm{~mL}$ double lid polythene bottle and transported to the lab. In the laboratory, $50 \mathrm{~mL}$ of the mixture were titrated with $\mathrm{HCl} \mathrm{N} / 10$ until the disappearance of the pink colour. A control experiment was conducted whereby; distilled water and the phenolphthalein indicator were used in the place of our water sample and titrated with $\mathrm{HCl}$ $\mathrm{N} / 10$. The amount of $\mathrm{CO}_{2}$ was obtained from the formula.

$\mathrm{CO} 2(\mathrm{mg} / \mathrm{L})=($ burette decrease of control test - burette decrease of sample $) \times 17.6$

\subsubsection{Dissolved Oxygen}

Measurement of dissolved oxygen involved the fixation of the gas in situ and its titration in the laboratory. On the field, after collecting the water sample in a $125 \mathrm{~mL}$ Winkler's bottle, we added $1 \mathrm{~mL}$ of $\mathrm{MnCl}_{2}$ and $1 \mathrm{~mL}$ of $\mathrm{KOH}+\mathrm{KI}$ solutions known as Winkler's reagent. The 
solution was homogenised by gently swirling the bottle which was closed firmly and transported to the laboratory. In the laboratory $1 \mathrm{~mL}$ of concentrated $\mathrm{H}_{2} \mathrm{SO}_{4}$ was added to the mixture to dissolve the white precipitate formed. Later on, we extracted $50 \mathrm{~mL}$ of the fixed sample using a measuring cylinder which was poured into a beaker and 2 to 3 drops of starch indicator was added. The mixture was titrated against the Sodium thiosulphate solution of concentration N/80 until the decolourisation of the blue black colour. The amount of oxygen gas in the sample was expressed in $\mathrm{mg} / \mathrm{L}$ and calculated thus:

$\mathrm{O}_{2}(\mathrm{mg} / \mathrm{L})=$ Initial burette reading -final burette reading. The value in percentage is obtained by conversion with a table that relates temperature to the concentration of oxygen.

\subsubsection{Nitrates and Orthophosphates}

The measurement of nitrates and orthophosphates was achieved by colorimetric analysis, using a spectrophotometer of mark $\mathrm{HACH}$ DR/3900 after calibration instrument using distilled water, $10 \mathrm{~mL}$ of sample water were put into the spectrophotometer tube cell to which were added Nitraver V and Phosver III reagents for the respective parameters to be measured. The results were read over the wavelengths of $500 \mathrm{~nm}$ and $490 \mathrm{~nm}$ respectively. These results were expressed in $\mathrm{mg} / \mathrm{L}$

\subsubsection{Oxydability}

Oxydability was measured in the laboratory by volumetric analysis. In a beaker of $500 \mathrm{~mL}$, $200 \mathrm{~mL}$ of the water sample were poured to which added $2 \mathrm{~mL}$ of $\mathrm{NaHCO}_{3}$ (monosodic carbonate). At the beginning of boiling, $20 \mathrm{~mL}$ of $\mathrm{KMnO}_{4}(\mathrm{~N} / 80)$ was added and left to boil for 10 minutes it was then left to cool under a running tap after which $5 \mathrm{~mL}$ of $\mathrm{H}_{2} \mathrm{SO}_{4} 25 \%$ and $20 \mathrm{~mL}$ of Mohr's salt (Ammonium and iron sulphate) were added successively. The mixture obtained was titrated against $\mathrm{KMnO}_{4}(\mathrm{~N} / 80)$ until the observation of a pink colour. The result obtained were expressed in $\mathrm{mg} / \mathrm{L}$ and calculated thus;

$$
\text { Oxydability }\left(\mathrm{mg} / \mathrm{L} \text { of } \mathrm{O}_{2}\right)=\frac{\mathrm{Vi}-\mathrm{V} 0}{2} \times 3.95
$$

$\mathrm{V}_{\mathrm{i}}=$ change inburette's volume using our sample water

$\mathrm{V}_{\mathrm{o}}=$ difference in volume using water as control experiment

\subsection{Biological Parameters Water Samples for Biological Analysis}

Samples for biological analyseswere left for sedimentation for 24 hours at room temperature for decantation and measure of the base. Isolation and identification were carried out using two methods: direct observation (staining and mounts between slides and cover slide) and after in vitro culture. The deposits obtained werequantified (measurement of the volume of the pellet), then homogenized and two sub-samples of $60 \mathrm{~mL}$ are taken, one for direct observation and the other for culture experimentation. One of the sub-samples is distributed in 12 test tubes ( $5 \mathrm{~mL}$ of pellet per tube); then $0.5 \mathrm{~mL}$ formol (fixative) is introduced into each tube as well as a few drops of dye (Lugol or MIF). The contents of the tubes are centrifuged at $500 \mathrm{rpm}$ for 5 minutes using a centrifuge of the brand MEDIFRIGER. The surface of the pellet, which is richer in parasites, is collected up by means of a micropipette, mounted between slides for microscopic observation at 400 and 1000 magnification, with the help of Olympus CK2 microscope. 
For culture, two techniques and two culture media were used. The technique of direct inoculation of $5 \mathrm{~mL}$ of pellet measured on a solid medium in the presence of a bacterial sheet of Escherichia coli, or the technique after filtration in which $10 \mathrm{~mL}$ of sample is taken, diluted to $25 \%$ with distilled water and filtered over cellulose acetate membranes with a porosity of $1.2 \mu \mathrm{m}$. After filtering, the filter is cut into four, each portion is placed on the surface of petri dishes containing one of the Non Nutritive Agar (NNA) (Pelandakis et al., 2002) media comprising of Sodium phosphate, Potassium phosphate, Sodium Chloride, Magnesium sulphate, Calcium Chloride and agar with a final $\mathrm{pH}$ of $7.0+/-0.2$ at $25^{\circ} \mathrm{C}$, or by the application of the PAS (saline solution) that has a similar composition except the absence of agar and the enrichment of the culture medium with Escherichia coli. The finalpH of $6,8+/-0.2$ required for the optimal growth of the amoeba. Incubation is at 37, 40, 44, 47 and $50^{\circ} \mathrm{C}$ (Puzon et al., 2009) for 2 to 10 days. Throughout the incubation period, regular microscopic examinations of culture medium fragments at 400 and 1000 magnification, with the help of Olympus CK2 microscope. The morphological characteristics of free amoebae such as the cysts, the trophozoite and flagellated forms are identified and enumerated.

\subsection{Data Analysis}

The integral volume $(\mathrm{Vx})$ of the pellet is noted. After homogenization of the pellet, the precise volume $(\mathrm{Vy}=60 \mathrm{~mL})$ is taken and distributed in different test tubes. The final portion of each tube is distributed on slides, and then the number of organisms (cells) is counted. The total number obtained in the sample is calculated by multiplying the value obtained on all the slides by the fraction $\mathrm{Vx} / \mathrm{Vy}$ and the result is finally reduced to the liter and noted number of individuals per liter (Ind./L) (Ajeagah et al., 2010) . The collected data was processed, grouped by seasons, using the Microsoft Excel 2010 program and the SPSS software version 20.0. As the data did not follow a normal distribution, the dependence relationships between the physicochemical and biological parameters were evaluated by Spearman's " $r$ " correlation test. These analyzes were performed using the SPSS software version 2:0.0 and the results were appreciated at the $1 \%$ and $5 \%$ security thresholds. The Kruskal-Walis $(\mathrm{H})$ and Mann Whitney "U" tests were used to measure spatial distribution dynamics of biological densities and to verify whether mean abundances vary significantly from one parameter to another, from one station to another or from one month to anotherat the safety level of $1 \%$ to $5 \%$.

\section{Results and Discussion}

\subsection{Physico-chemical Results}

The physico-chemical results recorded in the Olezoa stream and the Abieurgue stream of Yaounde are presented in Figure 2 (physical) and figure 3(chemical). The temperature oscillated around an average of $25 \pm 2{ }^{\circ} \mathrm{C}$ in both rivers and the humidity level remained above $50 \%$ at all seasons, showing a humid area. Suspended matter (SS) varied significantly from one watercourse to another with a maximum average of $381 \mathrm{mg} / \mathrm{L}$ in the Abiergue stream during long dry season (LDS). Colour did not vary much except for A1 (529 Pt-Co), same for turbidity. Dissolved oxygen registered value of $40 \%$, showing a deficit of oxygenation. 


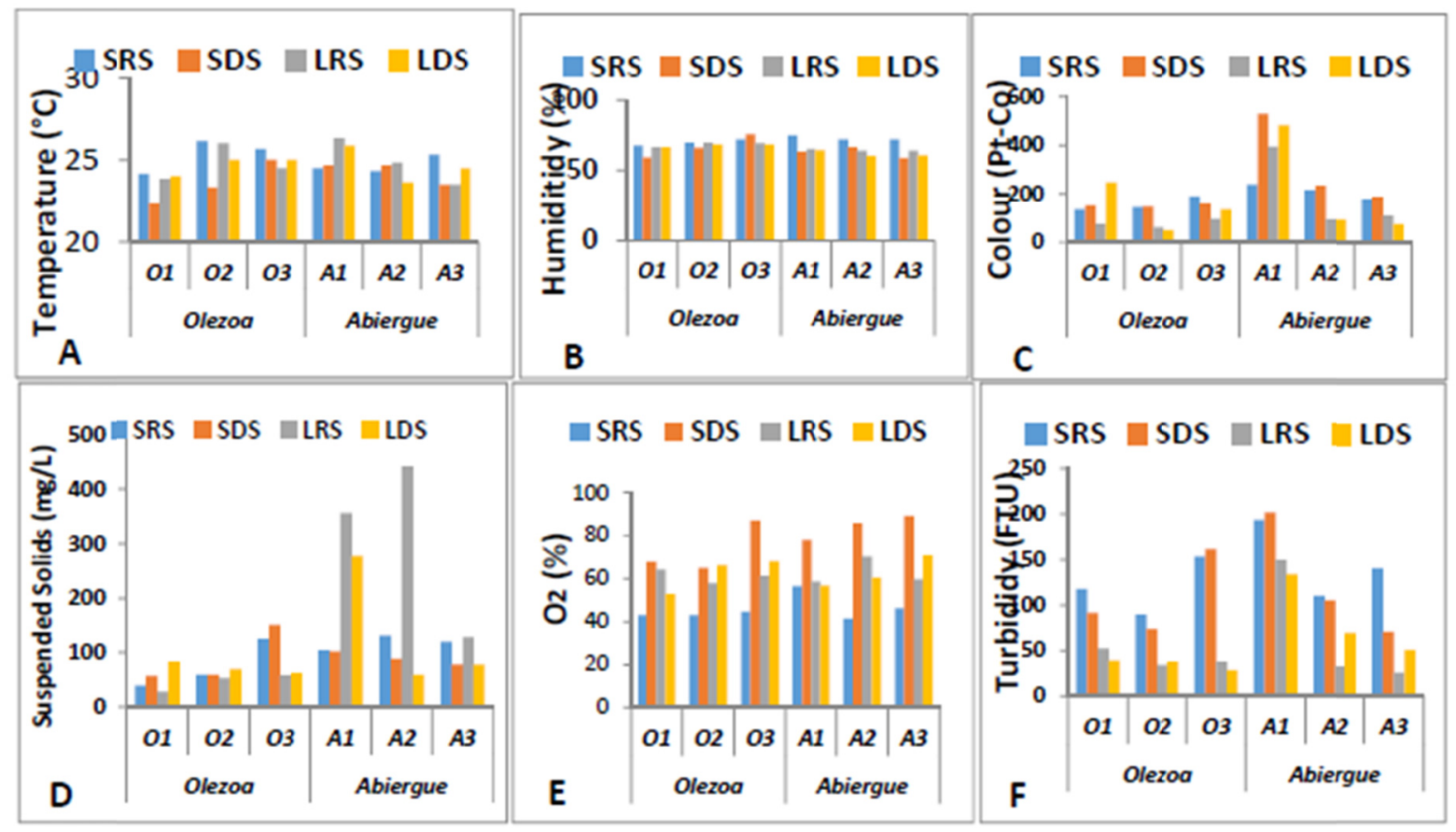

Figure 2. Spatio-temporal variation of physical parameters of the streams studied (A) temperature, (B) humidity, (C) colour, (D) suspended solids (E ) Dissolved oxygen and (F) turbidity

Concerning chemical parameters illustrated on figure 4, the $\mathrm{pH}$ remain around an average value of $6.9 \pm 0.4 \mathrm{uc}$, showing the low acidity to basicity of water. High values of nitrates $(10.9 \mathrm{mg} / \mathrm{L})$ and phosphates $(11.02 \mathrm{mg} / \mathrm{L})$ reveal a high pollution and eutrophication of the ecosystems assesses. The amount of dissolved organic matter was expressed as BOD5 and COD in the studied water points and the averages remained around $75 \mathrm{mg} / \mathrm{L}$ (BOD5), respectively, with average amplitude of $25 \mathrm{mg} / \mathrm{L}$ and $400 \mathrm{mg} / \mathrm{L}$ (COD), the values being significantly higher in the Abiergué waterways (Figure 3). 

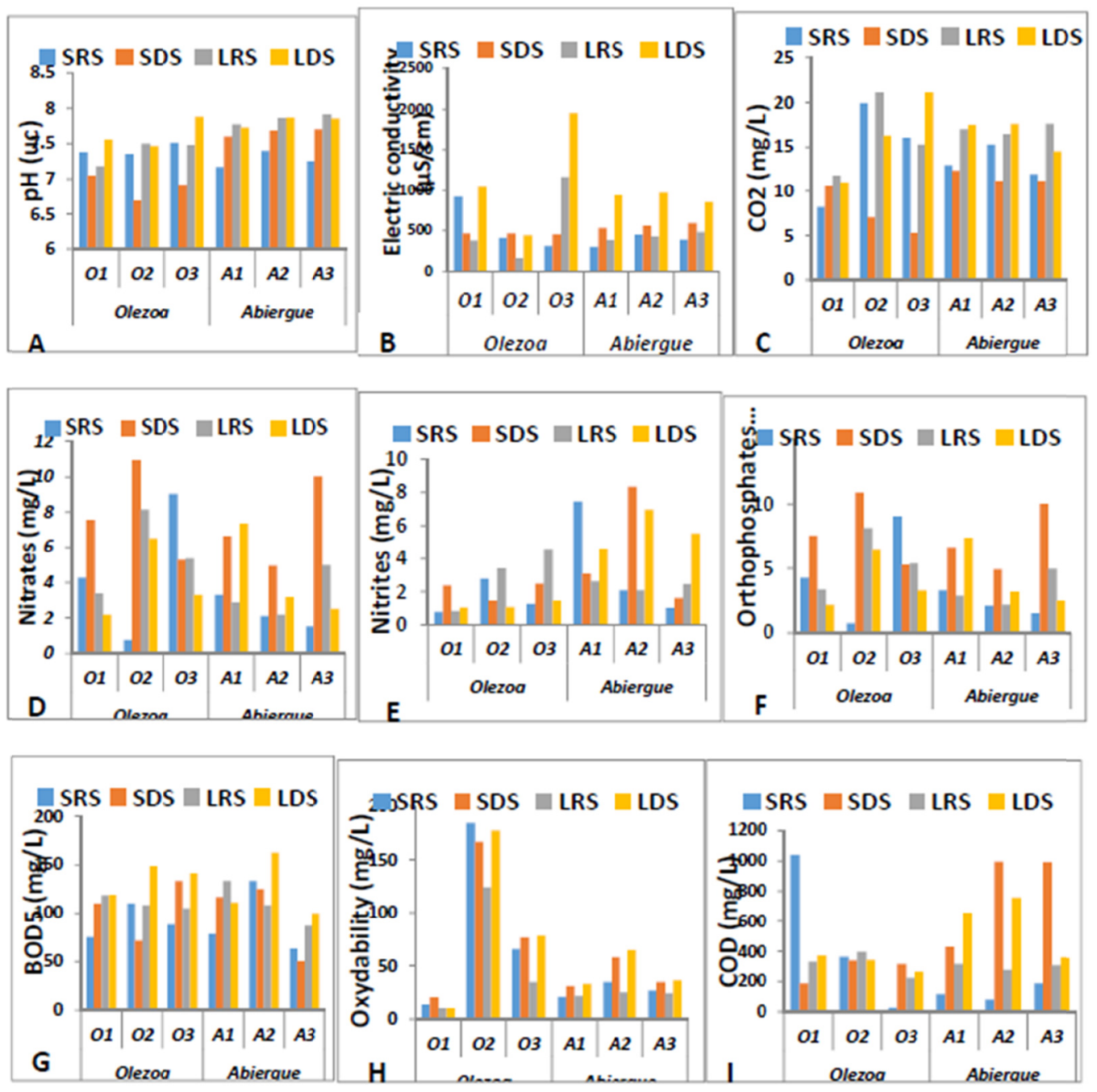

Figure 3. Spatio-temporal variation of chemical parameters of the streams studied (A) $\mathrm{pH},(\mathrm{B})$ Electric conductivity, (C) CO2, (D) nitrates, (E ) nitrites, (F) orthophosphates, (G) BOD5,

(H)oxydability and (I) COD

\subsection{Biological Results}

\subsubsection{Morphological Aspect and Description of Free Living Pathogenic Amoebae}

The free pathogenic amoebae isolated and identified belong to the genera Acanthamoeba, Balamuthia, Naegleria, Vanella and Hartmanella. The forms frequently observed in our samples are the cysts and the trophozoites. There was a high variation in the size and morphology of the amoebae. Those of Acanthamoeba are polygonal as presented in figure 6 with the presence of a double wall (an external ectocysts and an internal endocysts) measuring 10 to $26 \mu \mathrm{m}$. The size of the trophozoites varies between 18 and $50 \mu \mathrm{m}$. 


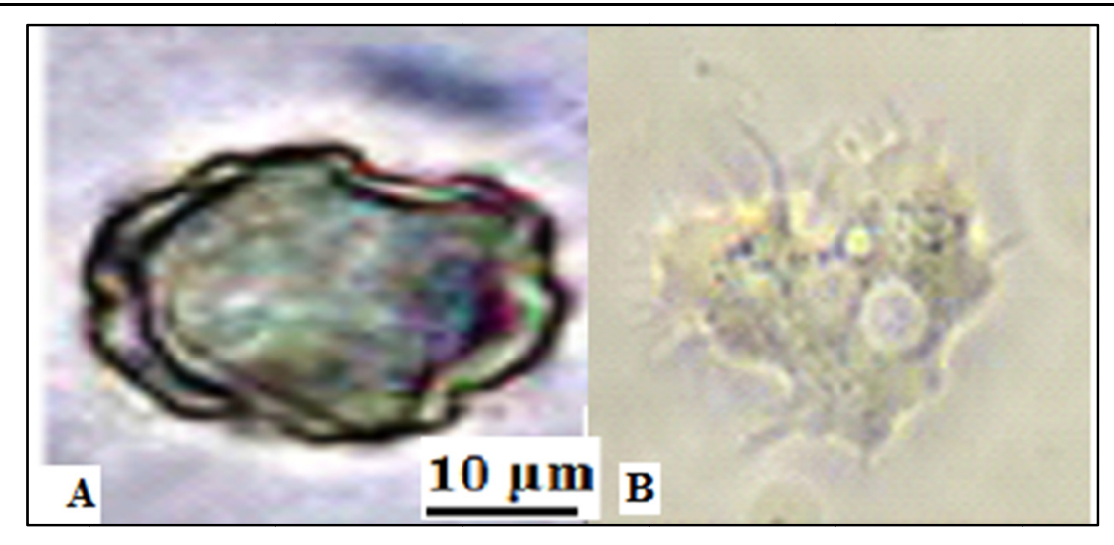

Figure 4. Cystic (A) and trophozoite (B) formsof genus Acanthamoebai dentified in our samples

Naegleria presents round cysts with a double wall of 12 à $30 \mu \mathrm{m}$ and a more visible nucleus. The nucleus of $5 \mu \mathrm{m}$ is limited by a nucleaire membrane. The trophozoite is elongated, with the nucleus present in the upper half. It measures about 30 to $70 \mu \mathrm{m}$. Naegleria is an amoeba flagellate, as it has a transitory, pear-shaped flagellate stage along with amoeboid trophozoite and resistant cyst stages in its life cycle. Naegleria exists in three forms (Figure 5). The amiboide trophozoite of 8 to $30 \mu \mathrm{m}$ of diameter is long and larger at the front than at the base. These parasitic forms present lobopodes, on eithr side of the ectoplasm. At the $2 / 3$ anterior and $1 / 3$ posterior, a unique, round nucleus of $5 \mu \mathrm{m}$ of diameter is identified. The trophozoite is the feeding, dividing, and infective stage for humans.

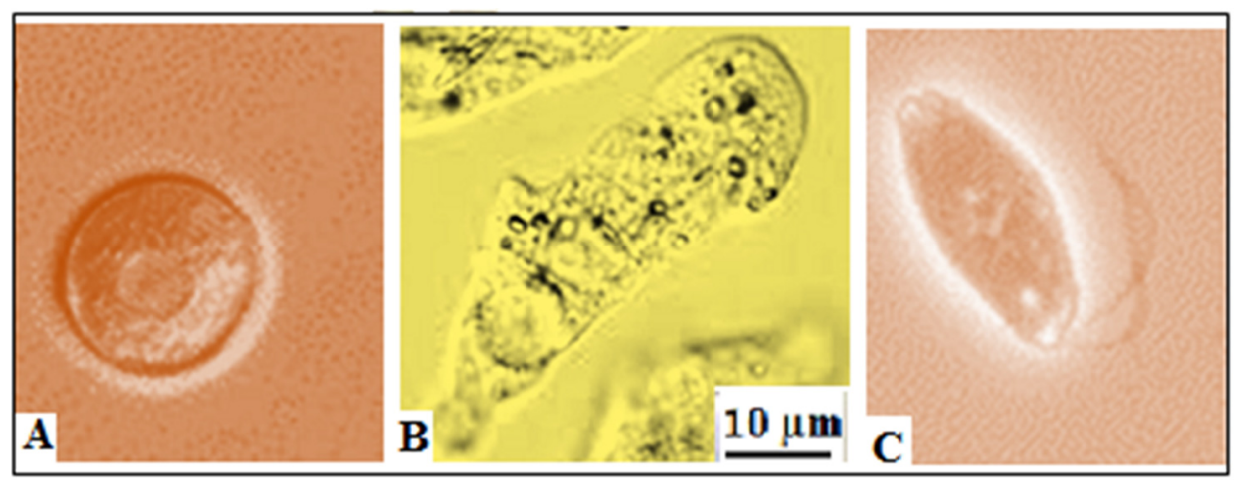

Figure 5. Different forms of Naegleria (A) Cyst, (B) trophozoite and (C) flagellated forms The free pathogenic amoebae Balamuthia(Figure 6) is present in the cystic form of 16 of 30

$\mu \mathrm{m}$ of diameter. It is round, and presents a triple wall; a thin irregular external wall (ectocysts), an intermediary mesocysts and a thicker internal endocysts. The trophozoite is characterised by an irregular form of 15 à $60 \mu \mathrm{m}$, with the presence of expansions. The nucleus is simple, round and presents a large dense nucleolus 


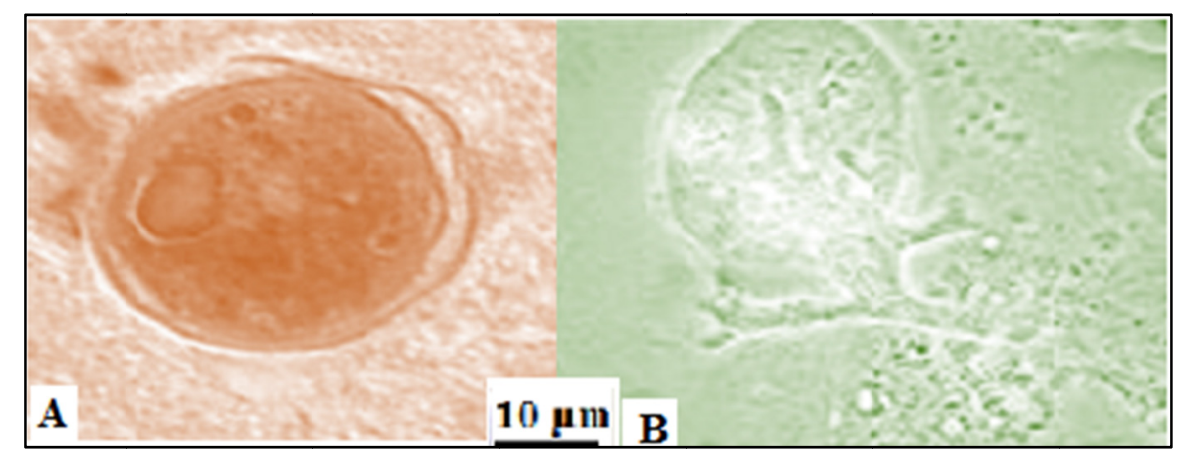

Figure 6. Forms of Balamuthia cysts and trophozoite identified in the samples

The genus Vannella (Figure 7) range from $9 \mathrm{~m}$ to $80 \mathrm{~m}$ in diameter. Vanella like other flabellate amoebae live on bio-films creeping along the flat surfaces sweeping up bacteria. Vannella produces long radiant pseudopods that allow them to float off to settle on the petridish.

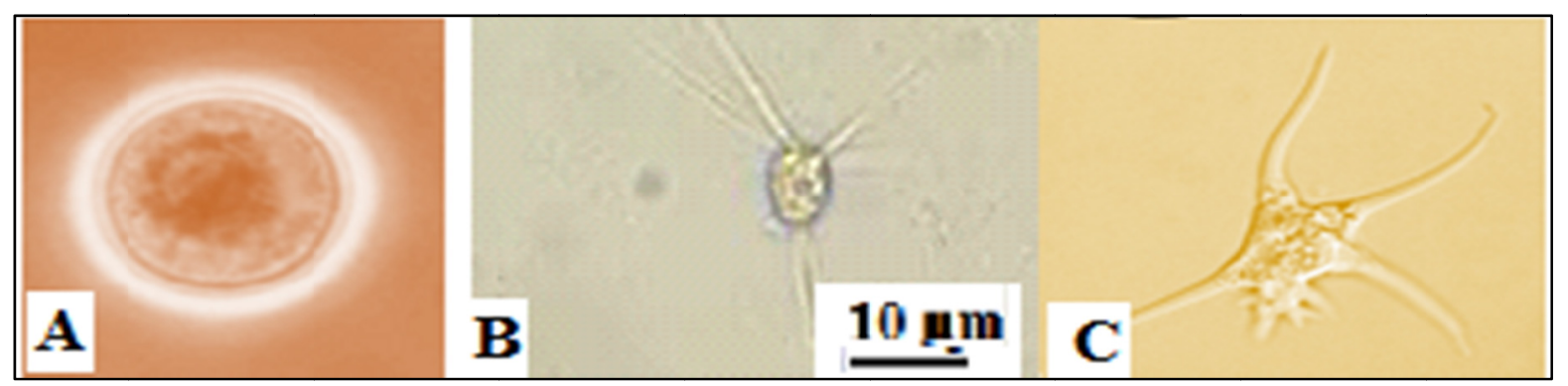

Figure 7. Cysts (A) and trophozoite (B and C) of Vanella identified in the samples

The Hartmanellaare free pathogenic amoebae (Figure 8) are 12-40 um long and the mean cyst diameter was about $6 \mathrm{um}$. No optically active inclusions were found in this species. The nucleus is characterised by the presence of a conspicuous chromatin bodies between nucleolus and a nuclear membrane and also flattened against the inner surface of the nuclear membrane.

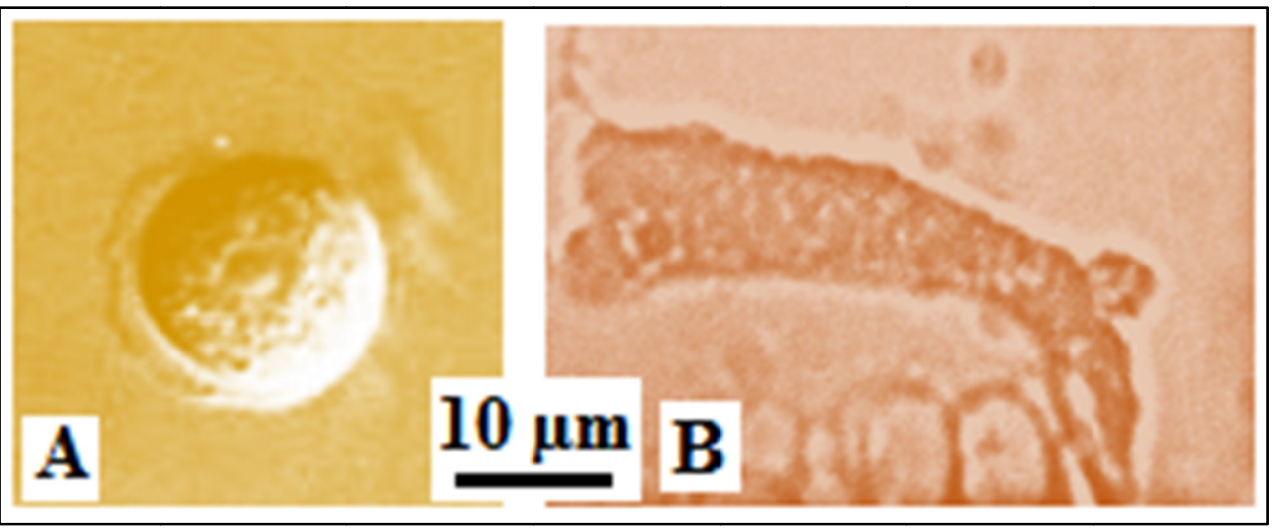

Figure 8. Cyst (A) and trophozoite (B) forms of Hartmanellai dentified in the samples 


\subsubsection{Spatio-temporal Variation of the Amoebae Density}

The average densities of the free living amoeba varied from 0 to 194 cell/L for all the species identified, with a maximum average of $194 \pm 34$ cell/L for Acanthamoeba, $86 \pm 13$ cell/L for Naegleria, $167 \pm 32$ cell/L for Vanella, $89 \pm 26$ cell/L and $64 \pm 17$ cell/L for Balamuthia. These free pathogenic amoebae were present in all the seasons, but more prevalent during the dry seasons (Figure 9). In the Olezoa stream, the most abundant genera was Vanella, followed by Acanthamoeba (O1).Inside the lake (O2), Acanthamoeba and Balamuthia are predominant, while Hartmanella present the highest density downstream of the olezoa. In the Abiergue stream, the high value wasregistered in A3.
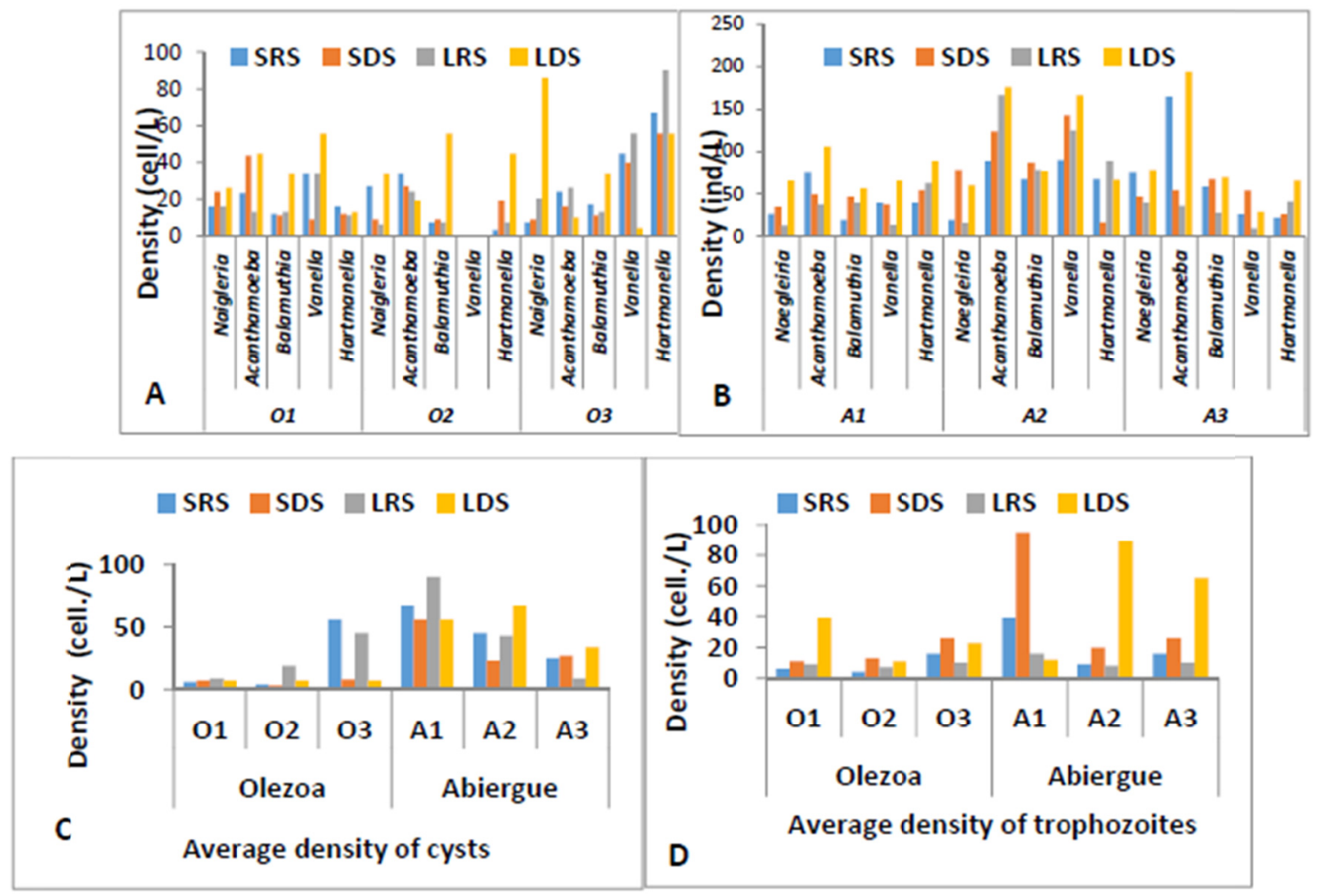

Figure 9. Seasonal distribution of the abundance (A and B) and density of cysts and trophozoites $(\mathrm{C}$ and $\mathrm{D})$ of free liviving pathogenic amoebae /L identified in the streams

There is a positive correlation between organic pollution and the free living amoeba. This correlation is positive and significant when the pollution is biodegradable ( $p>0.05$ value?). The density of amoeba evolves in the same direction with that of suspended solids, tropical temperature and the level of mineralisation as presented by the value of correlation between the conductivity of the aquatic ecosystem and the density of Acanthamoeba, Naegleria and Balamuthia as presented in table II. Vanella is significantly correlated with Nitrates, temperature, and biodegradable organic matter in the ecosystem $\left(0,689^{* *}\right)$ as presented in Table 1. 
Table 1. Correlations between free living pathogenic amoebas and physicochemical parameters*. Correlation is significant at the 0.05 level (2-tailed); **.Correlation is significant at the 0.01 level (2-tailed)

\begin{tabular}{|c|c|c|c|c|c|c|c|}
\hline & Nitrates $(\mathrm{mg} / \mathrm{L})$ & $\begin{array}{l}\text { COD } \\
(\mathrm{mg} / \mathrm{L})\end{array}$ & $\begin{array}{l}\text { Hygr. } \\
(\%)\end{array}$ & $\begin{array}{l}\text { Elec Cond. } \\
(\mu \mathrm{S} / \mathrm{cm})\end{array}$ & $\begin{array}{l}\text { Temp. } \\
\left({ }^{\circ} \mathrm{C}\right)\end{array}$ & $\mathrm{SS}(\mathrm{mg} / \mathrm{L})$ & $\begin{array}{l}\text { BOD5 } \\
(\mathrm{mg} / \mathrm{L})\end{array}$ \\
\hline Acanthamoeba & $-0,449 * *$ & $0,417 * *$ & $0,453^{*}$ & $0,464 * *$ & $0,302 *$ & $0,318^{*}$ & $0,466^{* *}$ \\
\hline Naegleiria & $-0,377^{*}$ & 0,187 & 0,228 & $0,444^{* *}$ & $0,733^{* *}$ & $0,417 * *$ & $0,583 * *$ \\
\hline Balamuthia & $-0,234$ & 0,179 & 0,047 & $0,391 *$ & 0,290 & 0,267 & $0,423 *$ \\
\hline Vanella & $0,748^{* *}$ & $0,582 *$ & $-0,472$ & 0,394 & $0,668^{* *}$ & 0,488 & $0,689 * *$ \\
\hline Hartmanella & $-0,032$ & 0,071 & $0,539^{*}$ & 0,353 & 0,159 & $-0,383$ & $0,821 * *$ \\
\hline
\end{tabular}

\subsection{Discussion}

The average temperature obtained is characteristic of the tropical zones and is prone to high variations due to the climatic mitigations noted in equatorial Africa.This temperature is favourable to the proliferation of several groups of free pathogenic amoeba isolated and identified in our studies (Figure 2-8). The amoebae are less tolerant species to temperature variations, especially to the genera Naegleria (Rodriguez-Zaragoza, 1994).A modification of the acidity of water could also have an effect on amoebic distribution in the streams in Yaounde (Figure 4A). The sensitivity of the amoebae to the $\mathrm{pH}$ is very variable and depends on the species considered.The amoebas such asNaegleria arefar lesstolerant with the presence of salt between $0.5 \%$ and $1 \%$ (Rodriguez-Zaragoza, 1994). Moisture remained higher than $50 \%$ would be also a factor favorable to the multiplication of Acanthamoebaand Balamuthia (De Toni et al., 2009). The values of BOD5, suspended matter are higher than the standards of WHO (2011) would translate a contamination of the surface water (Ajeagah et al., 2010) (Figures 4-9).

The trophozoite attaches to olfactory epithelium, where it follows the olfactorycell axon through the nasal cavity to the brain. This reproductive stage of the protozoan organism, which transforms near $25{ }^{\circ} \mathrm{C}$ and grows fastest as temperature increases, proliferates by binary fission( Page, 1988). The trophozoites are characterized by a nucleus and a surrounding cytoplasm halo. They travel by pseudopodia, which means that they extend parts of their body's cell membrane (the pseudopods) and then fill them with plasma to force locomotion. The pseudopods form at different points along the cell, thus allowing the trophozoite to change directions. In their free-living state, trophozoites feed on bacteria. In tissues, they phagocytize (consume by enclosing and then digesting prey) red blood cells and white blood cells, destroying tissue. This stage can be inhaled into the nasal cavity during swimming or diving (Patsyuk, 2016). This biflagellate form occurs when trophozoites are exposed to a change in ionic concentration as the case of the mineralised surface water in Yaounde, which presents ionic high concentration of Nitrates, phosphates and electrical conductivity (Figure 3). The transformation of trophozoite to flagellate occurs within a few hours. This amoebae are able to grow best at moderately elevated temperatures like in tropical aquatic ecosystems as presented 
in our data (Figures 4-9). Warm, fresh water with a sufficient supply of bacterial food provides a habitat for amoebae as the culture medium used in this study which is enriched with Escherichia coli. Man-made bodies of water, disturbed natural habitats, or areas with soil and unchlorinated/unfiltered water are locations where many amoebic infections are likely to occur (Table 1). N. fowleri thrives in the absence of other predators consuming its food supply. This hypothesis suggests that human disturbances such as thermal pollution increase $N$. fowleri abundance by removing their resource competitors (Puzon et al., 2009; Cervantes-Sandoval et al., 2010). Ameobo-flagellates have a motile flagellate stage that is designed for dispersal, which is advantageous when an environment has been cleared of competing organisms. Infections most often occur when water containing free pathogenic amoebais inhaled through the nose, where it then enters the nasal and olfactory nerve tissue, traveling to the brain through the cribriform plate.They feed on bacteria, but during human infections, the trophozoites consume astrocytes and neurons. Symptomsof free amoebic pathogenicity may include headache, fever and nausea. Later symptoms can include stiff neck, confusion, and lack of attention, loss of balance, seizures, and hallucinations (Blair et al., 2008). Once symptoms begin to appear, death will usually occur within two weeks.

Vannella are known to be infected naturally with a number of bacterial species (Rousset et al., 1994) and to harbour human pathogens. The genus has also been implicated with taste and odour problems in drinking water by the production of geosmin. Recently Vannella sp. Were found in association with Pseudomonas aeruginosa from a chronic corneal ulcer (Yu \& Painter, 2004), and although there was no suggestion that the amoeba was directly involved it was possible that they protected the bacteria against the Gentamicin and Cefalozin treatment. As regards the identifiedforms, the cysts were most abundant in our samples and on the culture media applied. Indeed they are the forms of resistances adapted to the low environmental sanitation of the medium. One also finds them on the culture media when the conditions become unfavourable. The whipped forms were seldomly found in our culture medium because of the short duration of survival of this form in the samples. They quickly encysts or are transformed by another more complex phenomenon. Acanthamoeba spp, Balamuthia, Naegleria, Vanilla spp Hartmannella spp. can harbour pathogenic microorganism which indicates the importance of these amoebae to public health.

Free-living amebae are found naturally in moist areasand natural polluted water and feed on the bacteria and nutrients found in these environments as presented by the high value of correlation between the indicators of organic pollution and the biodiversity of pathogenic free living amoebae as presented in Table 1. They can infect humans through the skin, olfactory epithelium, sinuses, corneal abrasions, or respiratory tract and are responsible for a variety of diseases, including cerebral edema, focal necrosis, granulomatous reactions in skin, multiple necrotic foci, corneal ulceration, and hemorrhagic necrosis. In addition, Acanthamoeba spp. infection can cause amebic keratitis, granulomatous amebic encephalitis, sinusitis, and cutaneous lesions.

\section{Conclusion}

The streams studied presents a considerable increase biodegradable organic matter concentrations. These amounts would be due to the domestic pollution and environmental mineralisation of the surface water. On the biological level these surface water points are 
contaminated with the free pathogenic living amoebae and the populations are thus exposed to the amoebic keratitis and encephalites due to the presence of Acanthamoeba, Naegleria, and Balamuthia, Vanella and Hartmanella isolated by direct techniques of observation and some culture essays with inoculation of the water sample on a solid medium in the presence of a bacterial sheet of Escherichia coli or the filtration technique and the culture of amoebae through petri dishes containing one of the Non-nutritive agar media or Page agar saline solution. The density of free pathogenic amoeba evolves in the same direction with that of suspended solids, turbidity, mineral content and the pollution status of the streams as presented by the high values of Biochemical Oxygen Demand and Chemical Oxygen Demand. This study poses thus a problem of public health, because this water is used by the populations for recreation, urban agriculture, domestic, artisanal industry and water adduction without any suitable treatment. We recommend to the authorities to jointly carry out reflexions with the populations and the urban municipality so that preventive initiatives are taken in the direction of the environmental protection and sensitization of the populations on the sustainable management of the water resources. An investigation of the connection between environment and the infections of the population by pathogenic amoebae is essential.

\section{References}

Ajeagah G. A., Njine T., \& Bilong, B. C. F. (2010). Seasonal Distribution of Enteric Opportunistic Cryptosporidium spp. Oocysts and Giardia spp. Cysts in a tropical water basin, Cameroon. Department of Parasitology, 44-57.

APHA (1998). Standard method for examination of water and wastewater (20th edition), Washington DC: American Public Health Association.

Blair, B., Sarkar, P., Bright, K. R., Marciano-Cabral, F., \& Gerba, C. P. (2008). Naegleria fowleri in Well Water. Emerging Infectious Diseases, 14(9), 1499-1501. https://doi.org/10.3201/eid1409.071076

Braun J.-J., Ndam Ngoupayou J. R., Viers J., Dupre B., \& Bedimo, J. P. (2005). Present weathering rates in a humid tropical watershed: Nsimi, South Cameroon. Geochim. Cosmochim. Acta, 69(2), 357-387. https://doi.org/10.1016/j.gca.2004.06.022

Cervantes-Sandoval I., Serrano-Luna J., \& Pacheco-Yépez J. (2010). Differences between Naegleria fowleri and Naegleria gruberi in expression of mannose and fucose glycoconjugates. Parasitol. Res, 106(3), 695-701. https://doi.org/10.1007/s00436-010-1727-z

De Toni A., Touron-Bodilis A., \& Wallet F. (2009). Effet du changement climatique sur les microorganismes aquatiques pathogènes: quelques exemples. Environnement, Risque et Santé, $4(8), 311-21$.

Institut national de cartographie. Cameroun (INC) (2008). Plan guide de Yaounde: Index des services et des rues. - Quadrillage de localisation. - Carton: "Yaounde et ses environs" Institut national de cartographie, Échelle [1:22 200]

Moreno-Mesonero, E. (2015). Techniques to Assess the Survival of the Heliobacter Pylori Inside Acanthamoeba Castellanii. Res Microbiol; DVC-FISH and PMA-9 PCR, 167(1), 29-34.

Page, F. C. (1988) In a new key to fresh water and soil Gymnamoebae with introduction for 
culture, Freshwater Biological Association, The Ferry House, Ambleside, Cumbria LA22 OLP, 91-92: 62.

Patsyuk M. K. (2016). New finds of naked Amoebae (Protista) in water Reservoirs of UkraineUDC 593.121 Vestnik zoologii, 50(4), 291-300.

Pelandakis, M., \& Pernin, P. (2002). Use of multiplex PCR and PCR restriction enzyme analysis for detection and exploration of the variability in the free-living ameba, Naegleria fowleri in the environment. App. Environ. Microbiol, 68, 2061-2065. https://doi.org/10.1128/AEM.68.4.2061-2065.2002

Petithory, J. C., Ardoin-Guidon, F., \& Chaumeil, C. (1998). Amibes et Flagellés intestinaux. Cahier de Formation Biologie Médicale Biopharma, 11, 255.

Puzon, G. J., Lancaster, J. A., \& Wylie, J. T. (2009). Rapid detection of Naegleria fowleri in water distribution pipeline biofilms and drinking water samples. Environ. Sci. Technol, 43, 6691-6696. https://doi.org/10.1021/es900432m

Rodier, J., Legube, B., \& Merlet, N. (2009). L'analyse de l'eau. $9^{\mathrm{e}}$ édition, Dunod, Paris, 1526p Rodriguez-Zaragoza, S. (1994). Ecology of free-living amoebae. Crit Rev Microbiol, 20, 225-41. https://doi.org/10.3109/10408419409114556

Rousset, J. J., Gaudebout, C., \& Rousset-Thevenoux, A. M. (1994). interrelations épidémiologiques entre protozoaires intestinaux à contage direct. Analyse statistique de 9471 examens et comparaison avec la littérature, Bull. Soc. Path. Exo., 87, 112-116.

Suchel, J. B. (1987). Les climats du Cameroun, 1(2).

Les climats du Cameroun, Jean-Bernard Suchel, Université de Saint-EtienneISBN 2950256902, 9782950256904, 1188 pages

Thomas, V. (2012). Amibes libres de l'environnement : écologie et interactions avec des micro- organismes pathogèenes émergents. Microbiologie et Parasitologie. Université Paris Sud - Paris XI. 65p.

Wéthé, J., Radoux, M., \& Tanawa, E. (2003). Assainissement des eaux usées et risques socio-sanitaires et environnementaux en zones d'habitat planifié de Yaoundé (Cameroun). Revue en Science de l'Environnement, 5, 23-25. 288. https://doi.org/10.4000/vertigo.4741

WHO (World Health Organization). (2011). Guidelines for drinking-water quality. (4 ${ }^{\text {th }}$ edition) Geneva, 564 p.

Yu, P. A. V., \& Painter, J. (2006). Surveillance for waterborne disease and outbreaks associated with recreational water-United States, 2003-2004. MMWR Surveill Summ, 55, 1-30.

\section{Copyright Disclaimer}

Copyright reserved by the author(s).

This article is an open-access article distributed under the terms and conditions of the Creative Commons Attribution license (http://creativecommons.org/licenses/by/3.0/). 